\title{
Response of the growth plate of uremic rats to human growth hormone and corticosteroids
}

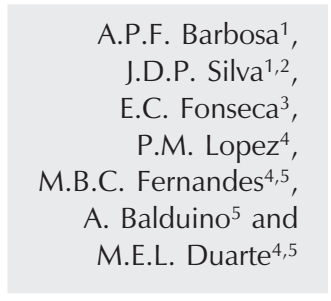

\author{
'Departamento de Patologia, Universidade de Ciências e Saúde de Alagoas, Maceió, \\ $\mathrm{AL}$, Brasil \\ ${ }^{2}$ Departamento de Histologia, Universidade Federal de Alagoas, Maceió, AL, Brasil \\ ${ }^{3}$ Departamento de Patologia, Universidade Federal Fluminense, Niterói, RJ, Brasil \\ ${ }^{4}$ Departamento de Histologia e Embriologia, Universidade Federal do Rio de Janeiro, \\ Rio de Janeiro, RJ, Brasil \\ ${ }^{5}$ Instituto Nacional de Traumatologia e Ortopedia, Rio de Janeiro, RJ, Brasil
}

\section{Correspondence}

M.E.L. Duarte

Instituto Nacional de Traumatologia

e Ortopedia

Rua Washington Luis, $61,6^{\circ}$ andar 20230-020 Rio de Janeiro, RJ

Brasil

Fax: +55-21-2242-1069

E-mail: mduarte@into.saude.gov.br

Received November 6, 2006 Accepted May 8, 2007

\begin{abstract}
Children with chronic renal failure in general present growth retardation that is aggravated by corticosteroids. We describe here the effects of methylprednisolone (MP) and recombinant human growth hormone (rhGH) on the growth plate (GP) of uremic rats. Uremia was induced by subtotal nephrectomy in 30-day-old rats, followed by 20 IU kg-1 day ${ }^{-1} \mathrm{rhGH}(\mathrm{N}=7)$ or $3 \mathrm{mg} \mathrm{kg}^{-1}$ day $^{-1} \mathrm{MP}(\mathrm{N}=7)$ or $20 \mathrm{IU} \mathrm{kg}^{-1}$ day $^{-1} \mathrm{rhGH}+3 \mathrm{mg} \mathrm{kg}^{-1}$ day $^{-1} \mathrm{MP}(\mathrm{N}=7)$ treatment for 10 days. Control rats with intact renal function were sham-operated and treated with $3 \mathrm{mg} \mathrm{kg}^{-1}$ day $^{-1} \mathrm{MP}(\mathrm{N}=7)$ or vehicle $(\mathrm{N}=7)$. Uremic rats $(\mathrm{N}=$ 7) were used as untreated control animals. Structural alterations in the GP and the expression of anti-proliferating cell nuclear antigen (PCNA) and anti-insulin-like growth factor I (IGF-I) by epiphyseal chondrocytes were evaluated. Uremic MP rats displayed a reduction in the proliferative zone height $(59.08 \pm 4.54$ vs $68.07 \pm 7.5 \mu \mathrm{m}, \mathrm{P}<0.05)$ and modifications in the microarchitecture of the GP. MP and uremia had an additive inhibitory effect on the proliferative activity of GP chondrocytes, lowering the expression of PCNA (19.48 $\pm 11.13 v \mathrm{~s}$ $68.64 \pm 7.9 \%$ in control, $\mathrm{P}<0.0005)$ and IGF-I $(58.53 \pm 0.96$ vs 84.78 $\pm 2.93 \%$ in control, $\mathrm{P}<0.0001$ ), that was counteracted by rhGH. These findings suggest that in uremic rats rhGH therapy improves longitudinal growth by increasing IGF-I synthesis in the GP and by stimulating chondrocyte proliferation.
\end{abstract}

\section{Introduction}

Longitudinal bone growth occurs by endochondral ossification in the growth plate, an avascular cartilaginous structure located between the epiphysis and metaphysis of the proximal and distal ends of long bones (1).
Key words

- Corticosteroids

- Growth hormone

- Renal failure

- Growth retardation

- Growth plate

- Insulin-like growth factor I
The cellular events that occur within the growth plate - chondrocyte proliferation, hypertrophy, and matrix secretion - result in chondrogenesis and longitudinal bone growth (2). During this highly regulated process, the chondrocytes from the growth plate follow a programmed ordered transition, giving ori- 
gin to three distinct zones: reserve zone, proliferative zone, and hypertrophic zone corresponding to different stages of chondrocyte differentiation (3). As the skeleton reaches sexual maturity, the fusion of the epiphysis with the metaphysis occurs, resulting in cessation of longitudinal growth (4).

Growth hormone $(\mathrm{GH})$ plays a central role in the promotion of growth of various tissues (1). GH stimulates the hepatic secretion of insulin-like growth factor I (IGF-I) and its release into the circulation that, in turn, controls the production of $\mathrm{GH}$ by the pituitary gland through a regulatory feedback loop in the hypothalamus. The stimulatory effect of $\mathrm{GH}$ on proliferating chondrocytes of the growth plate occurs through an indirect route that includes the activation of hepatic and local IGF-I production (5). In the epiphyseal plate, IGF-I acts in an autocrine or paracrine manner by stimulating the clonal expansion of proliferating chondrocytes (6).

Alterations in the regulation of the $\mathrm{GH} /$ IGF-I axis are among the main factors responsible for the short stature of children with chronic renal failure (7). Serum GH levels are generally normal or elevated in these children, indicating peripheral resistance to the action of $\mathrm{GH}$ in the uremic state (8). Although the exact mechanism has not yet been completely elucidated, this peripheral resistance to $\mathrm{GH}$ is probably mediated by a reduction in the serum levels of $\mathrm{GH}$ binding proteins and by reduced expression of hepatic GH receptor mRNA (9).

Glucocorticosteroids are routinely employed in different inflammatory diseases and as immunosuppressive agents for maintenance therapy after transplantation. Children using glucocorticosteroids frequently present important growth retardation and a reduction in bone mass, confirming the action of these drugs on epiphyseal cartilage (10). These clinical manifestations result from the inhibitory action of glucocorticos- teroids on chondrocyte and osteoblast proliferation, reduced expression of $\mathrm{GH}$ and IGF-I receptors in the epiphyseal plate (11), interference with the GH/IGF-I axis both at the systemic and cellular level (12), and a possible inhibitory action on hepatic $\mathrm{GH}$ receptor expression (13).

Growth retardation in children with chronic renal failure has a multifactorial origin. Factors that contribute to growth reduction include protein-calorie malnutrition, metabolic acidosis, peripheral resistance to $\mathrm{GH}$ in the target organs, anemia, renal osteodystrophy, and uremia itself altering the GH/IGF-I axis (14). Treatment of uremic children with $\mathrm{GH}$ induces a rapid and persistent increase in serum IGF-I levels that correlate positively with the rise in longitudinal growth, suggesting a role for IGF-I in GH-induced catch-up growth (15).

The aim of the present study was to evaluate the action of methylprednisolone (MP) and recombinant human growth hormone (rhGH) on the growth plate of uremic rats by morphological analysis and determination of the expression of markers of chondrocyte proliferation and biological activity in the epiphyseal growth plate of the rat tibia.

\section{Material and Methods}

After approval of the protocol by the Animal Care Committee (Federal University of Rio de Janeiro, Rio de Janeiro, RJ, Brazil), 42 weanling female Wistar rats aged 30 days and weighing 80-90 g were submitted to an acclimatization period of 1 week, with free access to water and standard rat chow containing $24 \%$ protein, $0.6 \%$ calcium, and $0.7 \%$ phosphorus (Purina, São Paulo, SP, Brazil). After 1 week, 28 rats underwent a two-stage 5/6 subtotal nephrectomy to induce renal failure. In the first stage (day 0), the left kidney was decapsulated and approximately the upper and lower thirds of the kidney were removed. The second stage nephrectomy was carried out 1 week 
later (day 8) and consisted of the removal of the entire right kidney after ligating the vascular pedicle. Surgical procedures were performed under ketamine/xylazine anesthesia. Fourteen animals were sham operated (renal decapsulation) in two stages, matching the time the nephrectomy procedures were done. After the first surgical procedure on day 0 , all animals were housed in individual semimetabolic cages at constant temperature with a 12-h light-dark cycle. All had free access to drinking water. Sham-operated control rats were pair-fed with uremic animals in terms of daily ingestion of protein and calcium, but the content of phosphorus in the diet of nephrectomized animals was raised to $1.2 \%$ to increase the severity of bone disease. Animals were weighed weekly and their body length determined during surgery, at the beginning of drug treatment, and at sacrifice by measuring the distance from the nose to the end of the tail with the animals under anesthesia.

Five weeks after the second surgical procedure (total nephrectomy or sham operation), the animals were divided into six groups of 7 subjects each and initiated on daily intraperitoneal (ip) injections of hormone for 10 days. Normal renal function rats and nephrectomized control rats (NX) received $i p$ injections of saline vehicle only. The NX $+\mathrm{GH}$ group consisted of nephrectomized animals treated with $20 \mathrm{IU}$ rhGH kg-1 day-1 (Humatrope ${ }^{\circledR}$, Lilly, Fegersheim, France); the NX + MP group consisted of nephrectomized animals treated with $3 \mathrm{mg}$ MP kg-1 day $^{-1}$ (Solu-Medrol, Pharmacia Brasil, São Paulo, SP, Brazil); the NX + GH + MP group consisted of nephrectomized animals treated with $20 \mathrm{IU}$ rhGH kg${ }^{-1}$ day $^{-1}+3 \mathrm{mg} \mathrm{MP} \mathrm{kg}^{-1}$ day $^{-1}$, and the MP group consisted of animals with normal renal function treated with $3 \mathrm{mg} \mathrm{MP} \mathrm{kg}{ }^{-1}$ day $^{-1}$.

At the end of the experiment, the animals were anesthetized and sacrificed by exsanguination by cardiac puncture. The serum obtained by centrifugation of the blood samples was stored for determinations of creatinine, urea nitrogen, calcium, and phosphorus.

For morphometric analysis, the left tibiae were fixed in $70 \%$ ethanol at $4^{\circ} \mathrm{C}$, dehydrated in graded solutions of ethanol and embedded undecalcified in methyl methacrylate. Five-micrometer sections were obtained with a high-impact microtome using disposable tungsten blades (Leica 2155, Nussloch, Germany) and stained with Alcian blue/PAS. The total width of the growth plate $(\mu \mathrm{m})$ was measured at equally spaced intervals comprising the whole extension of the epiphyseal plate; the width $(\mu \mathrm{m})$ of the zone occupied by proliferating or by hypertrophic chondrocytes was measured by the same method.

The right tibiae were fixed in $4 \%$ buffered paraformaldehylde solution for $48 \mathrm{~h}$, decalcified in $5 \%$ ethylene-diamine tetraacetic acid in $4 \%$ phosphate-buffered saline (PBS), $\mathrm{pH}$ 7.4, for approximately 10 days, and embedded in paraffin. Five-micrometer thick sections were deparaffinized, rehydrated and treated with 3\% hydrogen peroxide for $30 \mathrm{~min}$ (proliferating cell nuclear antigen, PCNA) or with $1 \%$ hydrogen peroxide for $10 \mathrm{~min}$ (IGF-I). Epitope retrieval was carried out with target retrieval solution (DakoCytomation, Carpinteria, CA, USA) at $95^{\circ} \mathrm{C}$ for $20 \mathrm{~min}$ (PCNA) or $0.125 \%$ trypsin (Sigma, St. Louis, MO, USA) in PBS for $10 \mathrm{~min}$ at room temperature (IGF-I). Non-specific blocking was carried out with $5 \%$ bovine serum albumin at room temperature for 1-2 $\mathrm{h}$ in a humidified chamber. Histological sections were then incubated overnight $(12 \mathrm{~h})$ at $4^{\circ} \mathrm{C}$ with $1 / 5000$ solution of mouse monoclonal anti-PCNA (DakoCytomation). For IGF-I staining, sections were incubated with 1/3000 human monclonal anti IGF-I (provided by Dr. Dennis Andress, University of Washington, Seattle, WA, USA) at $4^{\circ} \mathrm{C}$ for $48 \mathrm{~h}$. All primary antibodies were diluted in Antibody Diluent with Background Reducing Components 
(DakoCytomation). The slides were washed twice in PBS and incubated for $30 \mathrm{~min}$ in LSAB/LINK (DakoCytomation), again washed twice in PBS and treated for $30 \mathrm{~min}$ with LSAB/HRP streptavidin (DakoCytomation). Specimens were then developed with diaminobenzidine (Liquid DAB, DakoCytomation) for $1 \mathrm{~min}$ (PCNA) or $2 \mathrm{~min}$ (IGF-I), and counterstained with Harris hematoxylin.

The cell proliferation rate was determined by counting anti-PCNA-immunostained cells in the proliferative layer and is reported as percentage of the total number of cells in the proliferative zone. IGF-I expression was quantified by counting the number of immunostained cells in the hypertrophic and proliferative zones. The results are reported as the percentage of the total number of cells in both zones, respectively.

All histological sections were viewed by light microscopy using a Nikon microscope (Eclipse 800, Tokyo, Japan). All histomorphometric parameters were obtained by measurements made on digital photomicrographs (Coolpix 4300, Nikon, Tokyo, Japan) calibrated with a micrometer ruler and comprising the whole extension of the epiphyseal plate.

All markers were analyzed quantitatively using the ImagePro image analysis program (Media Cybernetics, LP, Silver Spring, MD, USA). Data are reported as means \pm SD. Comparisons of the six groups were made by one-way analysis of variance (ANOVA), and when the result of the $f$ test was significant $(\mathrm{P}<0.05)$, differences between specific means were tested by the Student $t$-test, with the level of significance set at $\mathrm{P}<0.05$.

\section{Results}

The installation of renal failure and uremia was confirmed by the serum urea nitrogen and creatinine levels, which were significantly higher in nephrectomized animals. There were no differences in serum calcium or phosphorus levels between nephrectomized and sham-operated animals (Table 1).

The weight and length gains of the control and experimental animals are presented in Table 2. Nephrectomized animals treated with rhGH $(\mathrm{NX}+\mathrm{GH})$ presented a significantly greater weight gain than animals with normal renal function and nephrectomized animals $(\mathrm{P}<0.05)$. Nephrectomized animals treated with the combination of rhGH and $\mathrm{MP}(\mathrm{NX}+\mathrm{GH}+\mathrm{MP})$ also presented a significantly greater weight gain at the end of the experiment compared to the control group and the NX + MP group. No significant difference in weight gain was observed between animals with normal renal function receiving or not MP (control and MP) and control nephrectomized animals (NX). The administration of rhGH resulted in a significantly greater length gain in nephrectomized animals compared to the control groups with

Table 1. Some serum biochemical parameters for all experimental groups of animals.

\begin{tabular}{lccrrrr}
\hline & C & NX & NX $+\mathrm{GH}$ & $\mathrm{NX}+\mathrm{MP}$ & $\mathrm{NX}+\mathrm{GH}+\mathrm{MP}$ & $\mathrm{MP}$ \\
\hline Serum urea nitrogen (mg/dL) & $11 \pm 1$ & $78 \pm 15^{*}$ & $54 \pm 10^{*}$ & $75 \pm 18^{*}$ & \multicolumn{1}{c}{$46 \pm 15^{*}$} & $16 \pm 9$ \\
Serum creatinine (mg/dL) & $0.48 \pm 0.12$ & $1.9 \pm 1.48^{*}$ & $1.48 \pm 0.51^{*}$ & $1.47 \pm 0.47^{*}$ & $1.28 \pm 0.71^{*}$ & $0.57 \pm 0.11$ \\
Serum calcium (mg/dL) & $11.12 \pm 3.64$ & $10.22 \pm 2.33$ & $11.82 \pm 3.02$ & $12.72 \pm 2.41$ & $10.14 \pm 1.63$ & $12.11 \pm 3.81$ \\
Serum phosphorus (mg/dL) & $8.54 \pm 1.79$ & $12.85 \pm 5.1$ & $10.84 \pm 1.18$ & $10.62 \pm 2.25$ & $8.95 \pm 1.65$ & $9.44 \pm 2.74$ \\
\hline
\end{tabular}

Data are reported as means $\pm S D$ for 7 animals in each group. $C=$ control rats with normal renal function pair-fed with the NX group; NX = nephrectomized rats; $\mathrm{NX}+\mathrm{GH}=\mathrm{NX}$ animals treated with $20 \mathrm{IU}$ recombinant human growth hormone (rhGH) $\mathrm{kg}^{-1}$ day $^{-1} ; \mathrm{NX}+\mathrm{MP}=\mathrm{NX}$ animals treated with $3 \mathrm{mg}$ methylprednisolone (MP) kg ${ }^{-1}$ day-1; NX $+\mathrm{GH}+\mathrm{MP}=\mathrm{NX}$ animals treated with $20 \mathrm{IU} \mathrm{rhGH} \mathrm{kg}{ }^{-1}$ day $^{-1}+3 \mathrm{mg} \mathrm{MP} \mathrm{kg}^{-1}$ day $^{-1} ; \mathrm{MP}$ $=$ rats with normal renal function treated with $3 \mathrm{mg} \mathrm{MP} \mathrm{kg}^{-1}$ day-1$^{-1}$. The duration of treatment with hormone or saline was 10 days.

${ }^{*} \mathrm{P}<0.05$ vs $\mathrm{C}$ and vs MP (Student $t$-test). 
intact or reduced renal function. Animals receiving the combination of rhGH and MP also displayed a significantly greater length gain in comparison with normal renal function animals $(\mathrm{P}<0.005)$.

\section{Epiphyseal growth plate morphometry}

The growth plate reached a significantly greater height in animals of the two experimental groups treated with rhGH $(243.02 \pm$ $28.2 \mu \mathrm{m}$ in $\mathrm{NX}+\mathrm{GH}$ and $212.23 \pm 14.1 \mu \mathrm{m}$ in $\mathrm{NX}+\mathrm{GH}+\mathrm{MP}$ ) compared to animals with normal renal function $(178.52 \pm 10.43$ $\mu \mathrm{m})$. Similarly, in both rhGH-treated groups the hypertrophic zone height $(108.78 \pm 20.46$ $\mu \mathrm{m}$ in $\mathrm{NX}+\mathrm{GH}$ and $93.07 \pm 8.13 \mu \mathrm{m}$ in $\mathrm{NX}$ $+\mathrm{GH}+\mathrm{MP}$ ) was significantly greater than in control animals $(75.81 \pm 13.73 \mu \mathrm{m})$. Renal failure $(162.47 \pm 23.86 \mu \mathrm{m}$ in NX) and treatment with MP alone $(176.3 \pm 22.22 \mu \mathrm{m}$ in MP) or in combination $(177.17 \pm 19.41 \mu \mathrm{m}$ in NX + MP) did not modify the final height of the epiphyseal growth plate. In contrast, $\mathrm{NX}+\mathrm{MP}$ animals showed a significant reduction in the proliferative zone height $(59.08$ $\pm 4.54 \mu \mathrm{m}$ ) when compared to animals with intact renal function $(68.07 \pm 7.5 \mu \mathrm{m}$; Figures 1 and $2 \mathrm{~A}$ ).

Micro-architectural alterations in the organization of proliferating and hypertrophic chondrocytes were in general small. Disturbed arrangement of chondrocytes, includ- ing loss of column alignment and linearity, was observed only in NX + MP animals and occurred in both the proliferating and hypertrophic zones of the growth plates (Figure $1)$.

\section{Immunohistochemistry}

Chondrocyte proliferative activity was evaluated by PCNA antibody expression in the proliferative zone of the growth plate cartilage. The number of proliferating chondrocytes in the growth plate of uremic untreated rats $(19.46 \pm 11.35 \%)$ was significantly decreased when compared with growth plates from control pair-fed rats (68.64 \pm $7.9 \%)$. Similar findings were observed in animals treated with MP $(33.55 \pm 15.74 \%)$ and NX + MP $(19.48 \pm 11.13 \%)(\mathrm{P}<0.005$ and $\mathrm{P}<0.0005$, respectively). PCNA expression by the chondrocytes of the proliferative zone of uremic rats treated with $\mathrm{rhGH}$ $(67.09 \pm 3.97 \%$ in $\mathrm{NX}+\mathrm{GH}$ and $54.26 \pm$ $3.4 \%$ in $\mathrm{NX}+\mathrm{GH}+\mathrm{MP}$ ) did not differ from vehicle-treated control animals. The combined treatment with both hormones (NX + $\mathrm{GH}+\mathrm{MP}$ ) did not reach the level of PCNA expression observed in the control group. However, it was statistically higher $(\mathrm{P}<$ 0.05 ) than in NX + MP animals (Figure 2B).

IGF-I expression was assessed in both the proliferative and hypertrophic zones of tibial growth plates from all groups. In the

Table 2. Weight and length gain of all groups of animals.

\begin{tabular}{lcccccc}
\hline & $\mathrm{C}$ & $\mathrm{NX}$ & $\mathrm{NX}+\mathrm{GH}$ & $\mathrm{NX}+\mathrm{MP}$ & $\mathrm{NX}+\mathrm{GH}+\mathrm{MP}$ & $\mathrm{MP}$ \\
\hline Initial body weight (g) & $62.45 \pm 4.45$ & $64.3 \pm 5.16$ & $74.11 \pm 10.61$ & $61.8 \pm 9.56$ & $63.71 \pm 8.37$ & $65.1 \pm 6.20$ \\
Weight gain (g) & $71.76 \pm 8.13$ & $65.33 \pm 24.56$ & $98.16 \pm 13.45^{\mathrm{a}, \mathrm{b}}$ & $68.28 \pm 17.78$ & $97.55 \pm 7.13^{\mathrm{a}, \mathrm{c}}$ & $85.37 \pm 11.54$ \\
Initial body length (cm) & $23.64 \pm 0.56$ & $23.63 \pm 1.43$ & $23.31 \pm 1.22$ & $22.57 \pm 1.17$ & $23.9 \pm 1.37$ & $23.28 \pm 0.53$ \\
Increase in body length (cm) & $8.93 \pm 0.34$ & $8.38 \pm 1.22$ & $10.73 \pm 1.67^{\mathrm{d}, \mathrm{e}}$ & $9.63 \pm 1.11$ & $10.43 \pm 0.87^{\mathrm{a}}$ & $9.57 \pm 0.98$ \\
\hline
\end{tabular}

Data are reported as means \pm SD for 7 rats in each group. $C=$ control rats with normal renal function pair-fed with the NX group; NX = nephrectomized rats; $\mathrm{NX}+\mathrm{GH}=\mathrm{NX}$ animals treated with $20 \mathrm{IU}$ recombinant human growth hormone (rhGH) $\mathrm{kg}^{-1}$ day-1; NX $+\mathrm{MP}=\mathrm{NX}$ animals treated with $3 \mathrm{mg}$ methylprednisolone (MP) kg ${ }^{-1}$ day ${ }^{-1} ; \mathrm{NX}+\mathrm{GH}+\mathrm{MP}=\mathrm{NX}$ animals treated with $20 \mathrm{IU} \mathrm{rhG} \mathrm{kg}^{-1}$ day $^{-1}+3 \mathrm{mg} \mathrm{MP} \mathrm{kg}^{-1} \mathrm{day}^{-1} ; \mathrm{MP}^{-1}$ $=$ rats with normal renal function treated with $3 \mathrm{mg} \mathrm{MP} \mathrm{kg}^{-1}$ day $^{-1}$. The duration of treatment with hormone or saline was 10 days. Initial body weight and length were measured during the first surgical procedure and weight and length gain were measured at the time of sacrifice. aP $<0.005$ vs C; bP $<0.05$ vs NX; ${ }^{\mathrm{CP}}<0.005$ vs NX + MP; $\mathrm{dP}<0.05$ vs C; ${ }^{\mathrm{e}}<0.005$ vs NX (Student $t$-test). 
Figure 1. Histological sections of proximal tibial growth plates viewed by light microscopy from sham-operated rats $(C)$ pair-fed with nephrectomized animals (NX) treated with recombinant human growth hormone (rhGH) $(\mathrm{NX}+\mathrm{GH})$, rhGH and methylprednisolone (NX + GH + MP), and animals with intact renal function treated with MP. The growth plate heights of uremic animals treated with $\mathrm{rhGH}(\mathrm{NX}+$ $\mathrm{GH}$ and $\mathrm{NX}+\mathrm{GH}+\mathrm{MP}$ ) were significantly higher than those of any of the other groups. Note the decrease in the organization of linear columns and the irregularity of proliferating and hypertrophic chondrocytes in NX + MP animals (arrows). Five-micrometer thick undecalcified sections stained with Alcian blue/PAS (original magnification: $40 \mathrm{X}) . \mathrm{P}=$ chondrocyte from the proliferative zone, $\mathrm{H}=$ chondrocyte from the hypertrophic zone.

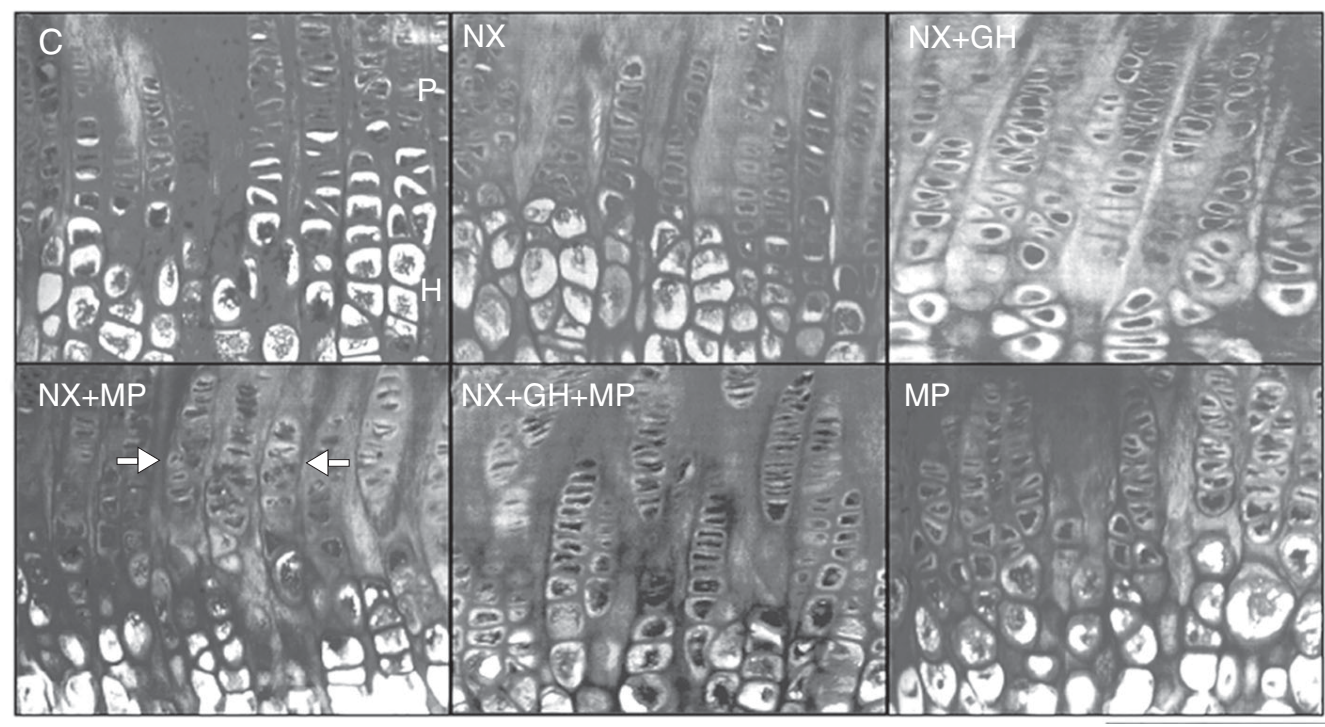

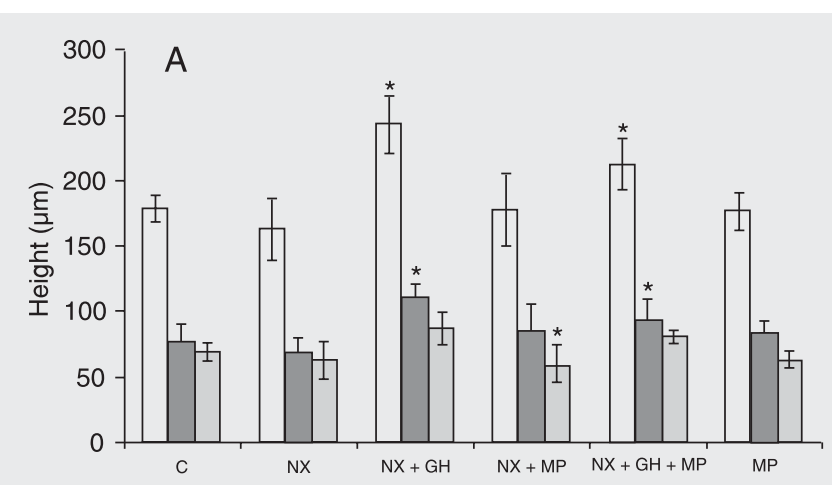

$\square$ Growth plate cartilage $\square$ Hypertrophic zone $\square$ Proliferative zone

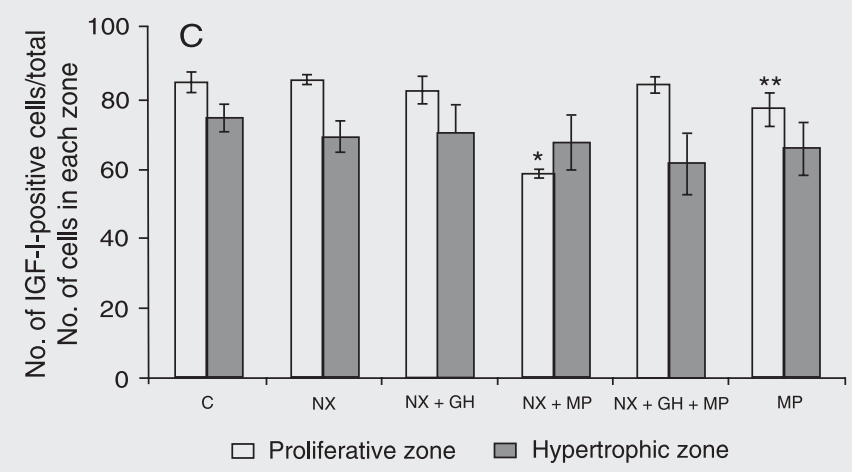

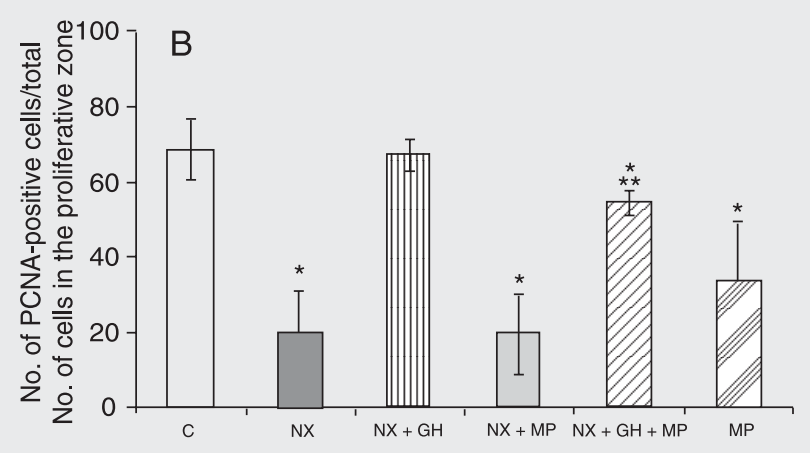

Figure 2. Effect of recombinant human growth hormone (rhGH) and methylprednisolone (MP) on the growth plate of uremic rats. $A$, Total width of the growth plate cartilage, width of the hypertrophic zone and proliferative zone for all groups of animals treated with hormone or saline for 10 days $\left({ }^{*} \mathrm{P}<0.0005\right.$ vs $\left.\mathrm{C}\right)$. B, Proliferating cell nuclear antigen (PCNA) expression assessed by immunohistochemistry. The number of positive cells is reported as percentage of the total number of cells in the proliferative zone of the growth plate $\left({ }^{*} P<0.05\right.$ vs $C$, ${ }^{* *} \mathrm{P}<0.05$ vs NX + MP). C, Insulin-like growth factor I (IGF-I) staining in proliferative and hypertrophic chondrocytes. The number of positive cells is reported as percentage of the total number of cells in the proliferative and hypertrophic zones of the growth plate, respectively $\left({ }^{*} \mathrm{P}<0.05\right.$ vs $\mathrm{C}$ and vs $\mathrm{MP},{ }^{* *} \mathrm{P}<0.05$ vs $\left.\mathrm{C}\right)$. All data are reported as means $\pm \mathrm{SD}$ for 7 rats in each group (Student $t$-test). For abbreviations, see legend to Table 1. 
proliferative zone, IGF-I expression was significantly lower in the NX + MP (58.53 \pm $0.96 \%)$ and MP $(76.98 \pm 4.69 \%)$ groups compared with pair-fed control rats $(84.78 \pm$ $2.93 \%$ ). Also, the combination of uremia and MP therapy had an additive inhibitory effect on IGF-I expression by the proliferative chondrocytes in NX + MP group $(\mathrm{P}<$ 0.0001 vs MP). However, this suppressive effect of MP on IGF-I expression by proliferative chondrocytes was abolished by rhGH treatment $(82.59 \pm 3.87 \%$ in $\mathrm{NX}+\mathrm{GH}$ and $84.09 \pm 2.27 \%$ in $\mathrm{NX}+\mathrm{GH}+\mathrm{MP})$. The expression of IGF-I by chondrocytes from the hypertrophic zone of the growth plate did not differ among groups (Figure 2C).

\section{Discussion}

The results of the present study confirm reports that rhGH promotes an increase of longitudinal growth in uremic animals (1619). In addition to the greater length, uremic animals treated with rhGH for 10 days showed a higher body weight when compared to control animals with or without reduced renal function. The greater length of uremic animals treated with rhGH was directly related to greater epiphyseal growth plate height, which, in turn, was due to an increase in the height of the hypertrophic zone. Furthermore, the stimulatory effect of rhGH on longitudinal growth may counteract, at least to some extent, the adverse effects of corticosteroid therapy on the growth plate. In the absence of $\mathrm{GH}$, corticosteroids substantially affected chondrocyte proliferation and IGF-I expression in the proliferative zone of the growth plate.

The somatothrophic effect of GH is exerted directly or indirectly by stimulating the systemic production of IGF-I by the liver cells and/or the local synthesis of IGF-I by the growth plate chondrocytes $(8,20)$. An indirect action through local and/or systemic IGF-I production could explain the increase in the hypertrophic zone height of uremic animals treated with rhGH. Although it is unclear how IGF-I contributes to longitudinal growth and how this factor is locally distributed in the growth plate, it has been demonstrated that it plays a role mainly in chondrocyte maturation and hypertrophy instead of inducing proliferation (21). Although both systemic and locally produced IGF-I seem to play an important role in longitudinal growth, liver-specific IGF-I depletion strikingly leads to growth rates comparable to those of wild-type animals (22), suggesting a central role for local IGFI production by growth plate chondrocytes. Recently, it has been demonstrated that IGFI is highly expressed by proliferating and pre-hypertrophic chondrocytes in the rat tibia growth plate (23) and also that local injection of GH regulates IGF-I expression by chondrocytes (6). Both findings support the hypothesis of a local action of IGF-I regulating chondrocyte maturation and hypertrophy.

While the final growth plate height was not affected by corticosteroids, the width of the proliferative zone was reduced in uremic animals treated with corticosteroids. The maintenance of the final growth plate height at levels similar to those observed in the control animals could be due to a delay in cartilage resorption and chondrocyte apoptosis (data not shown) in uremic animals receiving corticosteroids. This result could be attributable to the short duration of uremia and MP treatment.

The combined therapy with rhGH counterbalanced the adverse effects of corticosteroids and led to growth plate expansion. It is likely that rhGH, stimulates the proliferation of the chondrocytes from the proliferative zone, restoring the normal height of the proliferative zone and the total height of the growth plate. Although Hanna et al. (24) reported that the use of rhGH in nephrectomized animals resulted in a better level of organization of the proliferative zone chondrocytes, this finding was not confirmed in 
the present study.

The decreased expression of molecular markers of chondrocyte proliferating activity such as PCNA in animals with renal failure supports the view of reduced chondrocyte proliferation. This effect was more evident in corticosteroid-treated rats, possibly due to a higher susceptibility of proliferating cells to the effects of corticosteroids. Previous findings by Sanchez and He (25) demonstrated that proliferating cells are more vulnerable to corticosteroids, which may delay cell turnover and inhibit cellular activity. Nevertheless, the concomitant use of rhGH in uremic animals treated with corticosteroids led to partial recovery of PCNA expression by proliferating chondrocytes from the growth plate. This recovery may have been due to a stimulatory effect of $\mathrm{GH}$ increasing serum IGF-I levels, and thus compensating for the relative IGF deficiency observed in the uremic state.

Renal failure itself did not affect IGF-I expression in the proliferative or hypertrophic zones of the growth plate. The combination of renal failure and corticosteroid had an additive inhibitory effect on IGF-I expression by proliferative chondrocytes of the growth plate. This action, however, was counteracted by rhGH administration. Together with PCNA data, the neutralizing effect of rhGH might also be explained by an increase in IGF-I gene expression by proliferating chondrocytes (24), which contributes to chondrocyte maturation and plays an important role in the increase of the hypertrophic zone height in these animals.

Another new finding of the present study was the increase in IGF-I expression in the proliferative zone of the growth plate under the action of rhGH alone. This might explain the increase in the height of the hypertrophic zone through an autocrine-paracrine action by locally produced IGF-I, which controls chondrocyte maturation and hypertrophy
$(21,24)$. Although immunoreactivity to IGFI was observed in both zones of the epiphyseal plate, staining was more intense in the hypertrophic zone. Similar findings have been reported by other investigators $(24,26)$. Although the immunostaining for IGF-I was more intense in this zone, no quantitative difference in the expression of this peptide was observed between groups. This finding agrees with the histomorphometric results that showed no significant difference in hypertrophic zone height between animals of the experimental and control groups. The pattern of IGF-I staining did not permit us to define whether the chondrocytes are the site of synthesis or action of IGF-I, or both. The expression of IGF-I in proliferative zone chondrocytes suggests that other mechanisms, in addition to synthesis, are responsible for the IGF-I immunopositivity. Since immunoreactivity to IGF-I co-localizes with IGF-binding proteins, one may suppose that the degree of immunoreactivity depends on the presence of a higher or lower amount of these proteins (27).

The present results demonstrate that corticosteroids administered to uremic animals cause modifications in the micro-architecture of the epiphyseal plate and reduce the proliferative activity of chondrocytes in the proliferative zone. The antiproliferative effect of corticosteroids on epiphyseal plate chondrocytes was potentiated by uremia and partially counteracted by rhGH. Corticosteroids also impaired the expression of IGF-I by the chondrocytes of the proliferative zone of the epiphyseal plate. This effect was also potentiated by renal failure and neutralized by the concomitant action of rhGH. These findings suggest that rhGH therapy applied to uremic rats improves longitudinal growth by increasing IGF-I synthesis in the growth plate and by stimulating chondrocyte proliferation in the proliferative zone of the growth plate. 


\section{References}

1. Osafo J, Wei Y, Kenth G, Goodyer CG. Growth hormone during development. Rev Endocr Metab Disord 2005; 6: 173-182.

2. Nilsson O, Marino R, De Luca F, Phillip M, Baron J. Endocrine regulation of the growth plate. Horm Res 2005; 64: 157-165.

3. Roach HI, Mehta G, Oreffo RO, Clarke NM, Cooper C. Temporal analysis of rat growth plates: cessation of growth with age despite presence of a physis. J Histochem Cytochem 2003; 51: 373-383.

4. Weise M, De-Levi S, Barnes KM, Gafni RI, Abad V, Baron J. Effects of estrogen on growth plate senescence and epiphyseal fusion. Proc Natl Acad Sci U S A 2001; 98: 6871-6876.

5. Olney RC. Regulation of bone mass by growth hormone. Med Pediatr Oncol 2003; 41: 228-234.

6. Nilsson A, Isgaard J, Lindahl A, Dahlstrom A, Skottner A, Isaksson OG. Regulation by growth hormone of number of chondrocytes containing IGF-I in rat growth plate. Science 1986; 233: 571-574.

7. De Luca F. Impaired growth plate chondrogenesis in children with chronic illnesses. Pediatr Res 2006; 59: 625-629.

8. Tonshoff B, Kiepe D, Ciarmatori S. Growth hormone/insulin-like growth factor system in children with chronic renal failure. Pediatr Nephrol 2005; 20: 279-289.

9. Tonshoff B, Cronin MJ, Reichert M, Haffner D, Wingen AM, Blum $W F$, et al. Reduced concentration of serum growth hormone (GH)binding protein in children with chronic renal failure: correlation with GH insensitivity. The European Study Group for Nutritional Treatment of Chronic Renal Failure in Childhood. The German Study Group for Growth Hormone Treatment in Chronic Renal Failure. J Clin Endocrinol Metab 1997; 82: 1007-1013.

10. Sanchez CP, Goodman WG, Brandli D, Goldenhersh M, Murray C, Carlton E, et al. Skeletal response to recombinant human growth hormone (rhGH) in children treated with long-term corticosteroids. $J$ Bone Miner Res 1995; 10: 2-6.

11. Jux C, Leiber K, Hugel U, Blum W, Ohlsson C, Klaus G, et al. Dexamethasone impairs growth hormone (GH)-stimulated growth by suppression of local insulin-like growth factor (IGF)-I production and expression of $\mathrm{GH}$ - and IGF-I-receptor in cultured rat chondrocytes. Endocrinology 1998; 139: 3296-3305.

12. Chrysis D, Ritzen EM, Savendahl L. Growth retardation induced by dexamethasone is associated with increased apoptosis of the growth plate chondrocytes. J Endocrinol 2003; 176: 331-337.

13. Mehls $\mathrm{O}$, Himmele R, Homme M, Kiepe D, Klaus G. The interaction of glucocorticoids with the growth hormone-insulin-like growth factor axis and its effects on growth plate chondrocytes and bone cells. $J$ Pediatr Endocrinol Metab 2001; 14 (Suppl 6): 1475-1482.

14. Kuizon BD, Salusky IB. Growth retardation in children with chronic renal failure. J Bone Miner Res 1999; 14: 1680-1690.
15. Powell DR, Liu F, Baker BK, Hintz RL, Lee PD, Durham SK, et al. Modulation of growth factors by growth hormone in children with chronic renal failure. The Southwest Pediatric Nephrology Study Group. Kidney Int 1997; 51: 1970-1979.

16. Mehls O, Ritz E. Skeletal growth in experimental uremia. Kidney Int Suppl 1983; 15: S53-S62.

17. Nakano M, Kainer G, Foreman JW, Ko DJ, Chan JC. The effects of exogenous rat growth hormone therapy on growth of uremic rats fed an 8\% protein diet. Pediatr Res 1989; 26: 204-207.

18. Kawaguchi $\mathrm{H}$, Komatsu $\mathrm{Y}$, Hattori M, Ito K, Hizuka N, Takano $\mathrm{K}$. Potential effects of recombinant human growth hormone (r-hGH) on somatic growth in uremic rats. Acta Paediatr Jpn 1991; 33: 6-14.

19. Sanchez CP, Salusky IB, Kuizon BD, Abdella P, Juppner H, Goodman WG. Growth of long bones in renal failure: roles of hyperparathyroidism, growth hormone and calcitriol. Kidney Int 1998; 54 : 1879-1887.

20. Le Roith D, Bondy C, Yakar S, Liu JL, Butler A. The somatomedin hypothesis: 2001. Endocr Rev 2001; 22: 53-74.

21. Wang J, Zhou J, Bondy CA. Igf1 promotes longitudinal bone growth by insulin-like actions augmenting chondrocyte hypertrophy. FASEB J 1999; 13: 1985-1990.

22. Sjogren K, Liu JL, Blad K, Skrtic S, Vidal O, Wallenius V, et al. Liverderived insulin-like growth factor I (IGF-I) is the principal source of IGF-I in blood but is not required for postnatal body growth in mice. Proc Natl Acad Sci U S A 1999; 96: 7088-7092.

23. Reinecke M, Schmid AC, Heyberger-Meyer B, Hunziker EB, Zapf J. Effect of growth hormone and insulin-like growth factor I (IGF-I) on the expression of IGF-I messenger ribonucleic acid and peptide in rat tibial growth plate and articular chondrocytes in vivo. Endocrinology 2000; 141: 2847-2853.

24. Hanna JD, Santos F, Foreman JW, Chan JC, Han VK. Insulin-like growth factor-I gene expression in the tibial epiphyseal growth plate of growth hormone-treated uremic rats. Kidney Int 1995; 47: 13741382.

25. Sanchez CP, He YZ. Alterations in the growth plate cartilage of rats with renal failure receiving corticosteroid therapy. Bone 2002; 30 : 692-698.

26. Lazowski DA, Fraher LJ, Hodsman A, Steer B, Modrowski D, Han VK. Regional variation of insulin-like growth factor-I gene expression in mature rat bone and cartilage. Bone 1994; 15: 563-576.

27. Hill DJ, Clemmons DR, Wilson S, Han VK, Strain AJ, Milner RD. Immunological distribution of one form of insulin-like growth factor (IGF)-binding protein and IGF peptides in human fetal tissues. $J \mathrm{Mol}$ Endocrinol 1989; 2: 31-38. 